\title{
Effect of Abdominal Skin Massage and Warming Therapy on the Pain and Anxiety in the Breast Cancer Patients Who Underwent Hormone Injection: Short Review
}

\section{Jin Hee Jun ${ }^{1}$, Youn Ok Lee ${ }^{2}$ and Se-Na Lee ${ }^{2 *}$}

${ }^{1}$ Ambulatory Treatment Center, National Cancer Center, Goyang, Korea

${ }^{2}$ Department of Nursing, National Cancer Center, Goyang, Korea

\begin{abstract}
The purpose of this study was to identify effects of abdominal skin massage and warming therapy on the pain and anxiety to breast cancer patients who underwent hormone injections. The results of this study indicate that abdominal skin massage and warming therapy were highly effective in alleviating pain and anxiety in patients who underwent hormone injections
\end{abstract}

Keywords: Subcutaneous injections; Massage; Therapy pain; Anxiety

\section{Introduction}

The treatment of breast cancer depends on the age, stage, pathologic characteristics of the cancer and the psychological state of the patient and appropriate treatment methods such as surgery, radiation therapy, chemotherapy, hormone therapy and target therapy are used as adjunctive therapies to prevent recurrence.

Hormone therapy in breast cancer is a combination of estrogen receptors and progesterone receptors that can promote the growth of cancer cells and inhibits hormone secretion. It is used for the treatment of breast cancer recurrence prevention and recurrence [1].

For most oral medication, premenopausal women receive tamoxifen, a selective estrogen receptor modulator, and postmenopausal women use aromatase to inhibit the synthesis of estrogen. Its Inhibitors has been used [2].

In recent years, premenopausal breast cancer patients in their $30 \mathrm{~s}$ and 40s have high blood levels of hormones despite oral hormone therapy

Therefore, oral hormone and hormone injections are administered in parallel. When hormonal abdominal injections are initiated, they are injected repeatedly every 28 days for 2 to 5 years [3].

The authors observed fears and painful needle insertion before administering hormone injections to the outpatient room. High molecular weight hormone preparations are injected subcutaneously into the abdomen using a 16 gauge needle or higher. Before the hormone injection, the patients observed twisting and rubbing the abdomen and applying a warm pad to the injection site [2].

Previous studies of pain and anxiety due to skin piercing have been associated with invasive processes such as vascular punctures such as intramuscular, intravenous, and arteriovenous $[4,5]$.

There was no study of pain and anxiety associated with the injection of hormone drugs via subcutaneous abdominal injection.

We investigated the effect of abdominal skin massage and warming therapy on pain and anxiety reduction in the breast cancer patients who underwent hormone injection

\section{Methods}

The subjects for the study were 60 breast cancer patients who underwent hormone injections (20 in the control group, 20 in the abdominal skin massage group, and 20 in the warming therapy group). Abdominal skin massage was conducted following KSMA's (Korea science massage association) for 3-5 min before injection advice and warming therapy was executed at $48^{\circ} \mathrm{C}$ for $20 \mathrm{~min}$ at the injection site before injection. The results were checked using subjective and objective measurement tools.

Subjective pain measurements were self-checked by the Visual Analogue Scale (VAS), and objective pain was measured by the research observer using the objective pain scale. This scale is a checklist consists of facial expression, voice change, degree of sweating.

Anxiety measures were self-reported by the patient using visual analog scale (VAS) and state anxiety instrument. The study is shown in Figure 1 . The study was approved by the Institutional Review Board at the Cancer Center, Korea (NCC 2015-0229).

\section{Results}

After abdominal skin massage and warming therapy, subjective (Visual Analogue Scale, VAS) and objective (facial expression and vocal change) pain scores were significantly decreased $(p<0.001)$ (Table 1) Also, Anxiety state was significantly decreased comparing to control group ( $p=0.043$ ). There was no significant difference in subjective anxiety (VAS) between the control and the experimental group $(\mathrm{p}=0.052)$ (Table 2) Result of this study indicates that abdominal skin massage and warming therapy were highly effective to alleviate pain and anxiety to patients who underwent hormone injection.

*Corresponding author: Se-Na Lee, Department of Nursing National Cancer Center, 323 Ilsan-ro, Ilsandong-gu, Goyang 10408, Korea. Tel: +82-31-920-1335; Fax: +82-31-920-1268; E-mail: snlee0625@ncc.re.kr

Received October 07, 2017; Accepted October 13, 2017; Published October 20 2017

Citation: Jun JH, Lee YO, Lee SN (2017) Effect of Abdominal Skin Massage and Warming Therapy on the Pain and Anxiety in the Breast Cancer Patients Who Underwent Hormone Injection: Short Review. J Oncol Transl Res 3: 121. doi: 10.4172/2476-2261.1000121

Copyright: (c) $2017 \mathrm{Jun} \mathrm{JH}$, et al. This is an open-access article distributed unde the terms of the Creative Commons Attribution License, which permits unrestricted use, distribution, and reproduction in any medium, provided the original author and source are credited. 
Citation: Jun JH, Lee YO, Lee SN (2017) Effect of Abdominal Skin Massage and Warming Therapy on the Pain and Anxiety in the Breast Cancer Patients Who Underwent Hormone Injection: Short Review. J Oncol Transl Res 3: 121. doi: 10.4172/2476-2261.1000121

Page 2 of 3

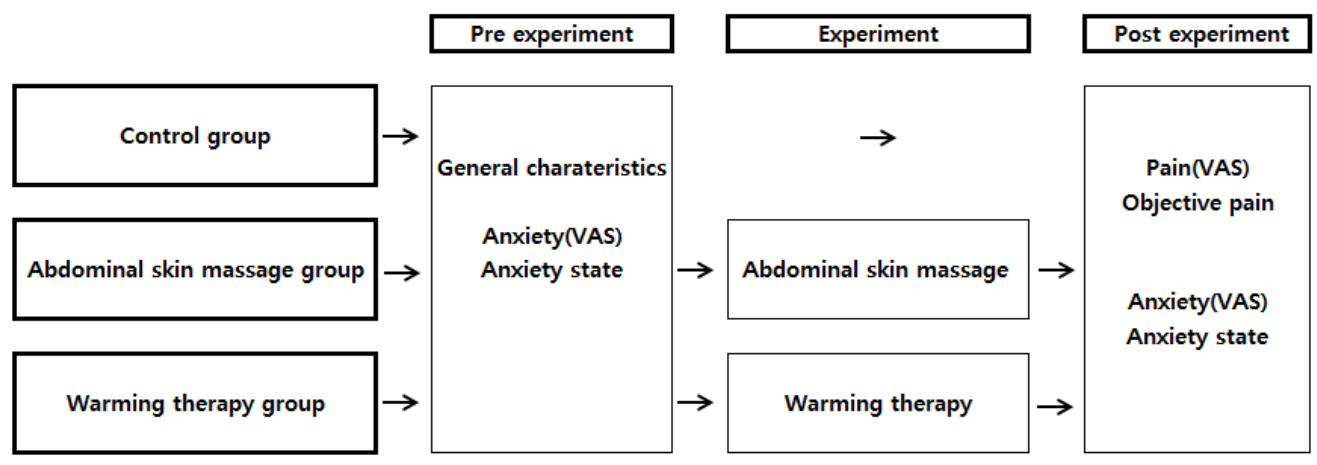

VAS: Visual Analogue Scale

Figure 1: Design of study.

\begin{tabular}{|c|c|c|c|c|c|c|}
\hline \multirow{2}{*}{ Variables } & Cont $^{\mathrm{a}} \cdot(\mathrm{n}=20)$ & Abdominal skin massage $^{b}(n=20)$ & Warm therapyc $(n=20)$ & \multirow{2}{*}{$\mathbf{F}$} & \multirow{2}{*}{$p$} & \multirow{2}{*}{ Scheff } \\
\hline & $M \pm S D$ & $M \pm S D$ & $M \pm S D$ & & & \\
\hline Pain (VAS) & $5.83 \pm 1.35$ & $3.00 \pm 1.65$ & $2.95 \pm 1.76$ & 21.21 & $<0.001$ & $a>b, c$ \\
\hline \multicolumn{7}{|l|}{ Objective pain } \\
\hline Facial expression & $4.85 \pm 0.99$ & $1.60 \pm 0.74$ & $0.75 \pm 0.55$ & 129.88 & $<0.001$ & $a>b>c$ \\
\hline Vocal change & $3.70 \pm 1.78$ & $0.55 \pm 0.51$ & $0.35 \pm 0.48$ & 57.75 & $<0.001$ & $a>b, c$ \\
\hline
\end{tabular}

VAS: Visual Analogue Scale; Cont: Control

Table 1: Pain score of post abdominal hormone injection $(n=60)$.

\begin{tabular}{|c|c|c|c|c|c|}
\hline \multirow{2}{*}{ Variables } & Pre & Post & \multirow{2}{*}{$t(p)$} & \multirow{2}{*}{$F(p)$} & \multirow{2}{*}{ Scheff } \\
\hline & $M \pm S D$ & $M \pm S D$ & & & \\
\hline \multicolumn{6}{|l|}{ Anxiety (VAS) } \\
\hline Cont ${ }^{a} .(n=20)$ & $4.80 \pm 2.07$ & $1.25 \pm 1.41$ & $3.91(<0.001)$ & $3.11(0.052)$ & \\
\hline Abdominal skin massage $^{b}(n=20)$ & $3.70 \pm 2.00$ & $0.50 \pm 0.89$ & $3.93(<0.001)$ & & \\
\hline Warm therapy ${ }^{c}(n=20)$ & $3.20 \pm 2.33$ & $1.20 \pm 1.51$ & $3.53(<0.001)$ & & \\
\hline \multicolumn{6}{|l|}{ Anxiety state } \\
\hline Cont ${ }^{\mathrm{a}} \cdot(\mathrm{n}=20)$ & $8.02 \pm 3.42$ & $3.45 \pm 3.08$ & $3.57(<0.001)$ & $3.33(0.043)$ & $a>b, c$ \\
\hline Abdominal skin massage $^{b}(n=20)$ & $5.95 \pm 2.88$ & $1.68 \pm 1.74$ & $3.81(<0.001)$ & & \\
\hline Warm therapy ${ }^{c}(n=20)$ & $7.45 \pm 3.65$ & $3.30 \pm 2.72$ & $3.87(<0.001)$ & & \\
\hline
\end{tabular}

Pre: Pre injection; Post: Post injection; VAS: Visual Analogue Scale; Cont: Control

Table 2: Difference in level of anxiety of pre, post abdominal hormone injection $(n=60)$.

\section{Discussion}

In our preliminary study, subjects preferred hyperthermia over cold therapy.

In a previous study, Choi's study [5] showed that warming therapy was effective in reducing pain when inserting an arteriovenous needle, and Jung's [6] reported that cold therapy was more effective at reducing pain than warming therapy

Nursing interventions for pain relief should be based on warming or cold therapy, depending on the patient's preference. In other words, pain is a subjective experience and no one can fully understand the suffering of others. Even if the same pain stimulus is given, the pain varies from person to person and the response to pain is different. Nursing interventions should be individualized according to individual preference.

In another study, pain and anxiety were reduced by using an abdominal wall warming pad before and after colonoscopy [7].
In a previous study, Sepeirs et al [8]. Reported that the use of local [8] anesthetics in 20 healthy adult subjects showed low predictive anxiety. In Buhse's study [4], 18 adults between 20 and 40 years of age were treated with EMLA, lidocaine and prilocaine cream prior to intramuscular injection to reduce fear and anxiety about injections. When hormonal abdominal injection therapy is started, it is injected repeatedly every month for 2 to 5 years. During the course of the experiment, the researchers observed that the patient's anxiety was high at the first time point, and another cause of anxiety was the visual effect of large needle size, which increased the patient's tension and anxiety. Patients were reminded of past painful experiences by repeated injections rather than one-time injections, and they were anxious from the day before the injection, and the pain was felt to be severe.

The application of abdominal skin massage and warming therapy is an effective alternative therapy that can be applied in the clinical field and is considered to be an effective non-medication nursing intervention to educate the patient. This study should be cautious in generalizing results with single institutional studies. 
Citation: Jun JH, Lee YO, Lee SN (2017) Effect of Abdominal Skin Massage and Warming Therapy on the Pain and Anxiety in the Breast Cancer Patients Who Underwent Hormone Injection: Short Review. J Oncol Transl Res 3: 121. doi: 10.4172/2476-2261.1000121

Page 3 of 3

\section{References}

1. Hwang E, Yi M (2014) Factors Influencing Quality of Life in Patients with Breas Cancer on Hormone Therapy. J Korean Acad Nurs 44: 108-117.

2. Naya $Y$, Hagiwara N, Takeuchi I, Mori M, Inagaki A, et al. (2014) 15 s skin icing using a frozen gel pack is effective for reducing goserelin injection pain. Urol Int 93: 202-206.

3. Park YH (2009) Drug therapy for breast cancer. J Korean Med 52: 963-974.

4. Buhse M (2006) Efficacy of EMLA cream to reduce fear and pain associated with interferon beta-1a injection in patients with multiple sclerosis. J Neurosci Nurs 38: 222-226.
5. Choi SH, Baek KH, Lim HB, Lee JY, Kim HJ, et al. (2006) The effect of warm and ice application for pain control caused by arteriovenous fistula needling under hemodialysis. J Korean Clin Nurs Res 12: 179-189.

6. Jung M (2002) The effect of warm and ice application on the pain and stress in needling under hemodialysis. Unpublished Master's Thesis, Kwandong University, Kangneung

7. Jeong KT, Yeon LH (2008) Effects of electric heating pad on abdominal pain and anxiety during the colonoscopy. J Korean Clin Nurs Res 14: 47-57.

8. Speirs A, Taylor K, Joanes D, Girdler N (2001) Anaesthetics: A randomised, double-blind, placebo-controlled, comparative study of topical skin analgesics and the anxiety and discomfort associated with venous cannulation. J Br Dent 190: $444-449$ 